\title{
Erratum to: "Current uses and trends in catalytic isomerization, alkylation and etherification processes to improve gasoline quality"
}

José M. Hidalgo", Michal Zbuzek, Radek Černý, Petr Jíša

Unipetrol Center of Research and Education - UNICRE,

Research Institute of Inorganic Chemistry, Areál Chempark,

43670 Litvinov-Záluží, Czech Republic

Received 17 October 2013; Accepted 20 October 2013

Abstract: The original version of the article was published in Cent. Eur. J. Chem. 12(1) (2014) pp. 1-13. Unfortunately, the original version of this article contains some mistakes in the text:

- The caption of Figure 7. A fixed bed unit converted to the UOP Par-Isom Process ${ }^{\mathrm{TM}}$

- Par Isom Process should be written as Par-Isom Process ${ }^{\text {TM }}$

- everywhere in the text LCC should be written as LLC

(c) Versita Sp. z o.o. 